\title{
“Konzil und Minderheit - I Concili e le Minoranze". Tagung der Gesellschaft für Konziliengeschichtsforschung, Rom, 10.-14. Oktober 2018
}

\author{
Johannes Grohe - Thomas Prügl \\ Pontificia Università della Santa Croce, Dipartimento di Storia della Chiesa, \\ Roma, Italien - Institut für Historische Theologie, Universität Wien, Wien, \\ Österreich \\ grohe@pusc.it-thomas.pruegl@univie.ac.at
}

Filippo Forlani (Rom) behandelt in seinem Beitrag La questione degli schiavi còrsi al Concilio di Pisa (1135) Kanon 3 des Pisanums, der den Menschenhandel verbietet, wobei darauf hingewiesen wird, dass dieses Verbot auch für Kauf und Verkauf von Personen mit Wohnsitz in Korsika gelten sollte, unabhängig davon, ob es sich um Männer oder Frauen handelt. Dieses Konzil wurde von Innozenz II. einberufen, um die Situation der Kirche zu erörtern, die durch die 1130 erfolgte Doppelwahl von Innozenz II. und Anaklet II. entstanden war, sowie Maßnahmen gegen das Konkubinat der Priester und gegen die Simonie zu beschließen. Kanon 3 ist im Zusammenhang mit dem von Innozenz II. nach langandauernden kriegerischen Auseinandersetzungen zwischen den Seerepubliken Genua und Pisa im Jahr 1133 herbeigeführten Friedensschluss von Grosseto zu sehen. Während der ersten Jahrzehnte des Jahrhunderts war es zu heftigem Streit um die Hoheit über die Insel Korsika gekommen. Da es dabei immer wieder zu Festnahmen von Gegnern kam, die dann zur Versklavung der Gefangenen führten, sahen sich die Konzilsväter veranlasst, sich mit dem Thema Sklaverei auseinanderzusetzen und dabei die korsische Bevölkerung, die als "Minderheit" Opfer in diesen Auseinandersetzungen war, mit Entschiedenheit zu verteidigen. Der Text des Kanons ist in seiner Art singulär, fügt sich aber gut in das Panorama des Lehramtes der Kirche zum Thema Sklaverei ein. 
Mit dem Konzil von Konstanz befassen sich zwei Beiträge. Im ersten Beitrag legt Sebastián Provvidente (Buenos Aires) mit Jean Gerson e la sua partecipazione nella causa Jean Petit durante il Concilio di Costanza (1414-1418) die komplizierte Behandlung des Tyrannenmords auf dem Constantiense dar. Im Zusammenhang mit der natio gallicana und den Sitzungen des Konzils von Konstanz (1414-1418) war der Fall Jean Petit Gegenstand heftiger Kontroversen, die zu vermeintlichen Mehrheits- und Minderheitspositionen darüber führten, ob die neun Thesen zur Rechtfertigung des Tyrannenmordes (am Herzog von Orléans) häretisch waren oder nicht. Der Beitrag analysiert einerseits, wie sich die Positionen von Mehrheit und Minderheit bezüglich der Sanktion der neun Thesen des Jean Petit gebildet haben, und andererseits, wie Jean Gerson, einer der Konzilsteilnehmer, der am meisten daran interessiert war, die vorherige Verurteilung dieser Thesen zu unterstützen, feststellen musste, dass innerhalb des Konzils im Zusammenhang mit der causa Jean Petit eine Veränderung wahrzunehmen war. Gersons Scheitern mit dem Anliegen, eine Verurteilung der Neun Aussagen zu erreichen, drohte Widersprüche in seinem Denken aufzudecken. In diesem Zusammenhang muss daran erinnert werden, was Gerson über die Lehrautorität der Konzilien gesagt hatte. Wenn sich nun ein Konzil in Glaubensfragen nicht irren konnte, was war dann mit Jean Petit und seiner Verurteilung in Konstanz geschehen? Wie konnte Gerson die Idee unterstützen, dass das Konzil die regula a Spiritu sancto directa war, die die wahre Auslegung eines biblischen Textes garantierte, angesichts der Ereignisse im Fall Petit? Nach dem Konzil stellte er in seinem Dialogus apologeticus (1418) fest, dass die entscheidenden Personen die Causa unionis dergestalt in den Vordergrund gestellt hätten, dass die Klärung dokrineller Fragen zurückstehen musste.

Ansgar Frenken (Ulm) untersucht sodann das Verhältnis von Mehrheiten und Minderheiten auf dem Constantiense bei der Behandlung von Reform oder Papstwahl - Das Konstanzer Konzil (1414-1418) in der Zerreißprobe. Diese kreisten um die Modalität der Papstwahl und die dabei von den verschiedenen nationes einzunehmende Rolle. Hatte es zu Beginn des Konzils unter den Konzilsvätern noch einen weitgehenden Konsens gegeben, so wich dieser spätestens nach dem Wiederaufbrechen des englisch-französischen Konflikts Mitte 1415 einem spannungsgeladenen Klima. Innere Spannungen unter den Konzilsteilnehmern traten immer stärker in den Vordergrund. Den Frontverlauf zwischen 'Mehrheit' oder 'Minderheit' auszumachen, ist dabei nicht einfach, da sich es sich nur bedingt um 'nationale' Grenzziehungen handelte und die Front zudem lange Zeit nicht so festgefügt war, als dass nicht auch Verschiebungen und Überschneidungen möglich gewesen wären. Bei der Bildung der beiden sich gegenüberstehenden Blöcke spielt die Ankunft der Spanier 
und die Bildung der fünften Konzilsnation eine wichtige Rolle sowie der Ausbruch des Nationen-Streites mit den Feindseligkeiten vor allem zwischen England und Frankreich. Diese Konflikte wurden mit der Frage verquickt, ob man der Kirchenreform Priorität einräumen oder gleich zur Wahl des neuen Papstes schreiten solle. Im Streit ersparte man dem jeweiligen Gegner nichts und bezichtigte die Gegenseite u.U. auch der Häresie. Hatte zunächst eine Gruppe um den römischen König Sigmund eine Mehrheit für den Vorrang der Reform auf ihrer Seite, so verschoben sich nach dem Beitritt der Kastilier zum Konzil im Sommer 1417 die Verhältnisse. Das Übergewicht einer Koalition von Kardinälen und den beiden Konzilsnationen Italica und Gallicana sowie den Kastiliern innerhalb der Hispanica wuchs, während die Gruppe um Sigmund, den Konzilsnationen Germanica und Anglicana sowie den Aragonesen an Boden verlor und zur 'Minderheit' wurde. Ein Ende Oktober des Jahres ausgehandelter Kompromiss, bei dem beide Seiten ihr Gesicht wahren konnten, ermöglichte einen erfolgreichen Konzilsabschluss. Einige bereits behandelte Reformdekrete wurden verabschiedet und dem künftigen Papst die Lösung von 18 Reformanliegen aufgetragen. Das Konzil konnte so mit der Wahl Martins V. zu einem versöhnlichen Ende gebracht werden.

Eine Minderheit außerhalb einer konziliaren Versammlung behandelt Alberto Cadili (Münster) mit Gli hussiti come (mancata) minoranza conciliare al Concilio di Basilea (1431-1438). 1433 wollte die Delegation der Hussiten in Basel die vier Artikel der Vereinbarungen von Eger vom Sommer 1432 (dem sog. "Richter von Eger"), d.h. in erster Linie nach der Bibel, diskutieren. Die Delegierten bestanden darauf, in freier Diskussion die andere Partei zu überzeugen oder sich von ihr überzeugen zu lassen; sie waren aber nicht bereit, sich in das Konzil inkorporieren zu lassen und damit zu einer konziliaren Minderheit zu werden, weil ja die Entscheidungsprozesse des Konzils auf dem Mehrheitsprinzip beruhten. Darüber hinaus bot das Konzil einen anderen "Richter" an: Es war das Konzil selbst, das sich als identisch mit der unfehlbaren Kirche verstand, so dass das "Monopol" der Interpretation der Schrift in der Synode gegenwärtig war. Auf diese Weise war es weniger von Interesse, die einzelnen, spezifischen Themen der vier Artikel zu erörtern. Die Hussiten akzeptierten diese Auffassung nicht, die für die Legitimität des konziliaren Entscheidungsprozesses grundlegend war. Sie waren nicht bereit, diesen neuen "Richter" anzuerkennen und unterwarfen sich ihm nicht.

Mit ihrem Beitrag Synode, Katholikentage und die protestantische Minderheit im langen 19. Jahrhundert in Ungarn behandeln Zsófia Bárány und Tibor Klestenitz (Budapest) das schwierige Verhältnis zwischen Katholiken und Protestanten:ImerstenDrittel des19.Jahrhunderts, während diekonfessionellen Auseinandersetzungen mit wechselnder Intensität weitergingen, tauchten in 
Ungarn Diskussionen über eine mögliche katholisch-protestantische Union auf. Das Neue an der Idee war, dass ihr die Utopie der "geistlichen nationalen Einheit" zugrunde lag. Die Idee dieser Union wurde auch im Entwurf des Nationalrats von 1822 erwähnt, jedoch dann im Verlauf der Beratungen fallen gelassen. Jenseits der nach wie vor heftigen konfessionellen Debatten gab es auf beiden Seiten Befürworter der Idee der Toleranz. Auf katholischer Seite vertraten sie Izidor Guzmics und János Horváth, beide Herausgeber zeitgenössischer ungarisch-katholischer Zeitschriften. Das Verhältnis zwischen Katholiken und Protestanten wurde in den 189oer Jahren durch den sogenannten kirchenpolitischen Kampf überschattet. Die liberale Regierungspartei strebte die Einführung der obligatorischen Zivilehe an, die von den Katholiken entschieden abgelehnt, von der Mehrheit der Protestanten dagegen akzeptiert wurde. Die politische Opposition der Katholiken wurde von einem Aristokraten, Graf Nándor Zichy, ins Leben gerufen, und seine Bewegung veranstaltete 1893 und 1894 zahlreiche katholische Kongresse auf regionaler Ebene, um gegen die Pläne der Regierung zu protestieren. 